\title{
Tinnitus services in the United Kingdom: a survey of patient experiences
}

\author{
Don McFerran ${ }^{1^{*}}$ D, Derek J. Hoare ${ }^{2}$, Simon Carr ${ }^{3}$, Jaydip Ray ${ }^{3}$ and David Stockdale ${ }^{4}$
}

\begin{abstract}
Background: Tinnitus service provision in the United Kingdom has been investigated from the healthcare provider's perspective demonstrating considerable regional variation particularly regarding availability of psychological treatments. An audiological-based tinnitus service, however, was reportedly available for all tinnitus patients in the UK. The aim of the current study was to define and evaluate nationwide tinnitus healthcare services from the patients' viewpoint.

Methods: Secondary analyses were performed on data from a 33-item questionnaire provided by the British Tinnitus Association. The questionnaire had been distributed via email and social media.

Results: Responses from 937 participants who had or had previously experienced tinnitus were analysed. All but one person had at some time consulted their GP. About one in five received medication in primary care. The majority were referred to secondary care, generally an ENT surgeon or audiovestibular physician; some were referred directly to audiological services. In secondary care the majority underwent audiometric testing and over half underwent MRI scanning. Drugs were prescribed less frequently in secondary care. About one third of patients were referred onwards from diagnostic services in secondary care to receive therapeutic interventions for tinnitus. Therapy was generally delivered by an audiologist or hearing therapist. Just under two fifths of people discharged from secondary care returned to their GP, with most returning within one year. Over a third of this group were rereferred to secondary care. Few patients saw a psychologist (2.6\%) though some psychological treatments were delivered by appropriately trained audiologists. Negative counselling from healthcare professionals in both primary and secondary care settings was reported.

Conclusions: Although the UK has developed a national service for patients with tinnitus many people find it difficult to access, being blocked at the primary care level or after secondary care diagnostic services. Many of those discharged from secondary care return to their GP within a short space of time and are re-referred to secondary care creating an unsatisfactory and expensive revolving-door pattern of healthcare. Despite psychological treatment modalities having the best evidence base for successful tinnitus management, only a minority of tinnitus patients ever get to meet a psychologist.
\end{abstract}

Keywords: Tinnitus, Primary care, Secondary care, Revolving door, Audiology, Psychology

\section{Background}

Tinnitus, defined as the perception of sound in the absence of the corresponding external sound source is a common symptom: epidemiological studies from several countries have shown point prevalence figures generally between 10 and $15 \%$ of the adult population [1]. In the

\footnotetext{
* Correspondence: donmcferran@aol.com

${ }^{1}$ Colchester Hospital University NHS Foundation Trust, Department of Otolaryngology, Essex County Hospital, Lexden Rd, Colchester, Essex CO3 3NB, UK

Full list of author information is available at the end of the article
}

UK, the largest survey of tinnitus prevalence was undertaken as part of the National Study of Hearing in England, surveying 48,313 people [2]. Tinnitus in this study was reported by $10.1 \%$ with $2.8 \%$ describing their symptom as being at least moderately annoying. For $0.5 \%$ of respondents their tinnitus was having a severe effect on the ability to undertake activities of daily living.

Although a cure for tinnitus remains elusive there are many strategies for helping to ameliorate the impact of the condition $[3,4]$ including explanation and 
reassurance, counselling, management of associated hearing loss, sound therapy and psychological modalities such as cognitive behavioural therapy (CBT) [5-7], mindfulness meditation [8] and acceptance and commitment therapy (ACT) [9].

There have been various attempts at producing a set of structured guidelines for the management of tinnitus: The Department of Health in England issued a consensus document that presented commissioning guidelines and best practice advice in 2009 [10]; the American Academy of Otolaryngology published evidence-based clinical guidelines in 2014 [11]. The National Institute for Health and Care Excellence (NICE) have published a Clinical Knowledge Summary regarding management of tinnitus [12] but have not, to date, produced a formal Quality Standard.

Several service evaluations have accounted UK National Health Service (NHS) tinnitus services from the perspective of general practitioners (GPs), audiologists or hearing therapists (in the UK, hearing therapists are health care professionals who specialise in the rehabilitation of patients with hearing loss, tinnitus and other otological symptoms, but generally do not become involved with audiological testing or fitting of hearing instruments) [13-15]. In those service evaluations, clinicians provided an overview of what they perceive that they offer to patients with tinnitus, what resources they have and use and the training they have undertaken. They also provided opinions on what make for a good tinnitus service and how effective they considered their care to be. Surveys of healthcare providers tell part of the story but do not necessarily define the services as perceived by the end user. A recent publication has evaluated the effectiveness of different tinnitus and hyperacusis therapies from an end user perspective in a single UK hospital [16]. They concluded the most effective components of interventions to be counselling, education, and CBT. The current study was a retrospective analysis of anonymised data collected by the British Tinnitus Association (BTA) [17] and was developed to account the patients' experience and evaluate nationwide tinnitus healthcare services from the patients' viewpoint.

\section{Methods}

This study was a service evaluation involving retrospective analysis of anonymised data originally collected by the BTA from its members to inform a cost of tinnitus care study [18]. Data were analysed with the support and permission of the data controller (DS). This use of the data complies with the governance procedures of the charity. As this study was a retrospective service evaluation and used only highly anonymised data for the sole purpose of service evaluation, individual consent was not sought, and research ethics committee review was not required [19].

\section{Questionnaire development}

A 33-item questionnaire was developed in an iterative process involving staff and members of the Professional Advisers' Committee of the BTA (tinnitus advisers, clinicians, researchers). Questions were developed based on experience with previous surveys of audiological tinnitus services [14], previous membership surveys conducted by the BTA (unpublished) and issues that had arisen during an assessment of the economic impact of tinnitus [18]. The 33 items comprised 5 demographic questions and 28 tinnitus specific questions (12 multiple choice, 13 multiple choice with an 'other' option and 3 open ended) (see Additional file 1).

The questionnaire was uploaded to an online data collection and analysis service, Survey Monkey [20]. The design used a separate page for each online question. No questions were mandatory. Participants were asked only to respond if they were resident in the UK, had, or previously had, tinnitus and had consulted their GP about tinnitus.

\section{Distribution}

The questionnaire went live on Survey Monkey on $14^{\text {th }}$ of October 2014 and remained open until $31^{\text {st }}$ of October 2014. A link to the questionnaire was emailed to 4446 email addresses on the British Tinnitus Association (BTA) database. These were BTA members, people who had sought advice from the BTA, or recent BTA website users. The link to the questionnaire was also sent out using social media to people following the BTA via Facebook or Twitter. There was no paper version of the questionnaire. No explicit age restriction was created.

\section{Data management}

Data were exported from Survey Monkey and managed in Excel. Two authors (DM and DJH) independently assessed the results to identify duplicate studies, those from outside the UK and any anomalous responses. Because of the anonymous nature of the study, it was not possible to ask respondents about missing data. It was assumed that questions were left blank when the respondent had no personal experience of that item or did not want to provide a response. DS was the data guarantor.

\section{Analyses}

Quantitative analyses were performed in Excel. Openended questions were analysed by developing coding categories for each type of response and assigning codes to individual responses within the Excel spreadsheet. The codes were generated by one author (DM) and independently verified by another (DJH). The codes were then collated and analysed. Responses to open ended questions were used where appropriate to provide illustrative quotes that supported or helped explain quantitative findings. 


\section{Results}

A total of 977 responses were received. Twenty of these were identified as duplicates where participants are assumed to have started the questionnaire, paused and then re-started afresh. Twenty responses were identified as coming from outside the UK, despite the instructions stating that the survey was intended for people in the UK. These 40 entries were discounted from the analysis. A further entry was from a respondent living on the Isle of Man. The Isle of Man is a British Crown Dependency and as such is not officially a component part of the UK. However, Manx healthcare shares some services with the North West region of the UK and it was therefore retained in the analysis. In total, 937 responses were subjected to analysis.

Responses were received from all regions of the UK (Table 1), though comparing responses to population density figures from the Office for National Statistics [21] showed a slight overrepresentation from the South East (13.74\% of UK population: $20.38 \%$ of survey respondents) and South West (8.40 of UK population: $13.34 \%$ of survey respondents).

Eight hundred sixty-six respondents identified their gender: 440 women, 425 men and 1 transgender. Eight hundred seventy-three people identified their age (Fig. 1). The modal group by age distribution was the group aged between 50 and 69. This concurs with epidemiological studies of tinnitus which generally show that tinnitus is most prevalent in this age group [2].

\section{Primary care}

All but one respondent had seen their GP at some point regarding their tinnitus. Nine hundred thirty-one

Table 1 The regional distribution of responses to the questionnaire survey $(n=937)$

\begin{tabular}{lll}
\hline Region & \multicolumn{2}{l}{ Respondents } \\
\cline { 2 - 3 } & $(\mathrm{n})$ & $(\%)$ \\
\hline England & 36 & 3.84 \\
North East & 104 & 11.10 \\
North West & 71 & 7.58 \\
Yorkshire and The Humber & 54 & 5.76 \\
East Midlands & 71 & 7.58 \\
West Midlands & 68 & 7.26 \\
East of England & 102 & 10.88 \\
London & 191 & 20.38 \\
South East & 125 & 13.34 \\
South West & 38 & 4.06 \\
Wales & 67 & 7.15 \\
Scotland & 9 & 0.96 \\
Northern Ireland & 1 & 0.11 \\
Isle of Man & &
\end{tabular}

respondents answered the question "Approximately how long did you have tinnitus for before you saw your GP?" (Fig. 2). The majority (71.0\%) made their first contact with their GP within 1 year of the onset of their tinnitus symptoms, with most of these (44.5\% of the total) presenting within three months of onset.

Respondents reported that at their GP appointments a variety of interventions were offered (Table 2). The most common intervention was onward referral to secondary care $(76.6 \%)$ after one or more GP appointments. Most frequently this referral was to the local ENT or Audiovestibular Medicine (AVM) service. Other common interventions included the supply of information (10.7\%) or prescription of drugs $(20.1 \%)$. When drugs were recommended, psychoactive drugs were the most common prescription, with 60 people reporting that they had been given an antidepressant, 26 had been given a hypnotic, and 2 had received an antipsychotic (Table 3 ). Nasal drugs were also commonly prescribed and seemed to be aimed at improving suspected Eustachian tube dysfunction. Twenty-four people received antibiotics. Twenty-five had been given betahistine but it is not clear whether this was because of suspected Ménière's disease or as an off-licence treatment of subjective idiopathic tinnitus. Approximately one in five respondents (19.5\%) reported that they did not receive any intervention from their GP. Negative statements made in response to open ended questions, such as "My GP didn't seem bothered and he didn't really want to explain anything to me, maybe he just didn't know enough about the subject. He could of sent me to see a specialist who could help me further" were common.

Six-hundred and eighty participants answered the question "If you were referred to hospital (ENT/Audiovestibular Medicine, or Audiology department), approximately how many times did you see your GP before you were referred?". Although just over half of respondents (55.4\%) reported that they were referred at their first visit and 79.8\% had been referred by their second GP appointment, $20.2 \%$ attended on three or more occasions before a referral was made (Fig. 3). Twenty-one people stated that they had to demand or formally complain before their GP would consider referral to secondary care. Typical free text entries from this group included "Been at varying times to GP over the years with tinnitus, some GPs do nothing, some try medication, had to fight to get ENT referral" or "I was frustrated at the lack of support from the GP and had to push for a referral to ENT". Five reported that they were still waiting for their secondary care appointments.

\section{Secondary care}

Pathways were defined for 673 respondents (Table 4). Referral to a hospital based ENT/AVM service or 


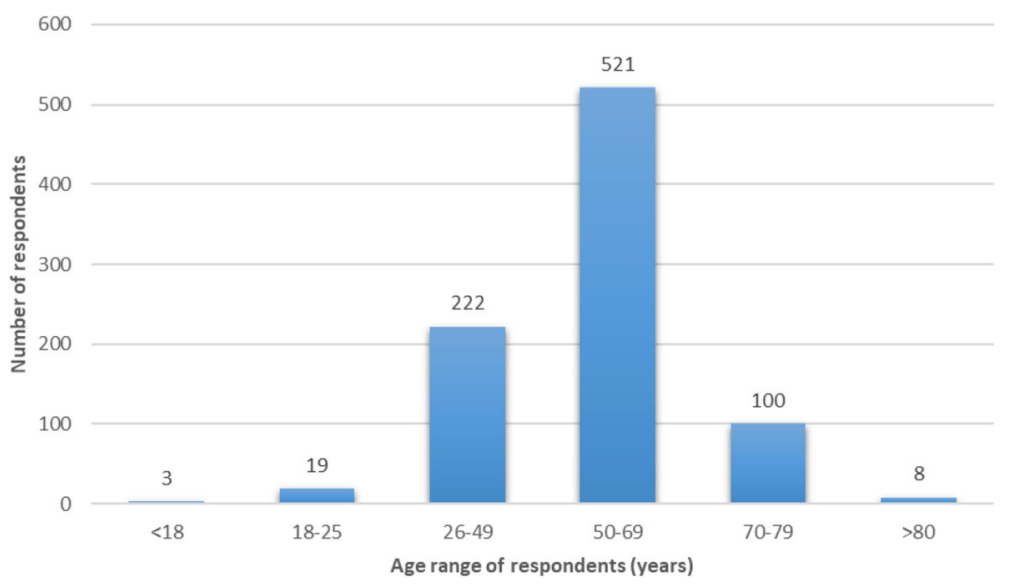

Fig. 1 The age distribution of survey respondents $(n=873)$

hospital-based Audiology service was most common. Although they were not asked directly, 32 respondents stated within responses to open-ended questions that they had gone down a private healthcare route, either because they had pre-existing private healthcare insurance, because they felt this was the only way of obtaining a timely referral, or because they felt this was the only way of obtaining a referral from their GP at all. It is likely that the number of people who did use private healthcare was underestimated here as it was not specifically included in any question's response option. Sixteen respondents identified their first point of contact with secondary care as being the radiology department for an MRI scan. It is likely that these patients had additional appointments with ENT or AVM.

Of the patients attending ENT/AVM, 294 described the diagnostic and therapeutic procedures that occurred at the first appointment or were booked from that appointment (Table 5). The majority $(90.1 \%)$ reported having an audiometric assessment. Over half (59.2\%) were referred for an MRI scan. Haematological testing was seldom requested (3.1\%), as was referral for CT scanning or ultrasound scanning $(2.1 \%)$. The proportion of patients prescribed drugs in secondary care was approximately half that in primary care $(10.1 \%$ vs $20.1 \%$ respectively) and the pattern of drugs prescription was very different (Table 3). In 12 of the 32 patients (37.5\%) who received drugs in secondary care, the drug was betahistine. Psychoactive drugs were infrequently prescribed in secondary care, being given to 4 out of 32 patients $(12.5 \%$ of those who received drugs). Similarly, nasal drugs and antibiotics were prescribed much less frequently in secondary care.

Two-hundred and forty-nine people identified the number of ENT/AVM appointments they had attended (Fig. 4). The majority (65.9\%) had a single appointment and only $6.4 \%$ had more than 3 appointments.

Ultimately, most people with tinnitus underwent audiometry through a variety of different pathways (Table 6). Seven-hundred and ten people responded to this

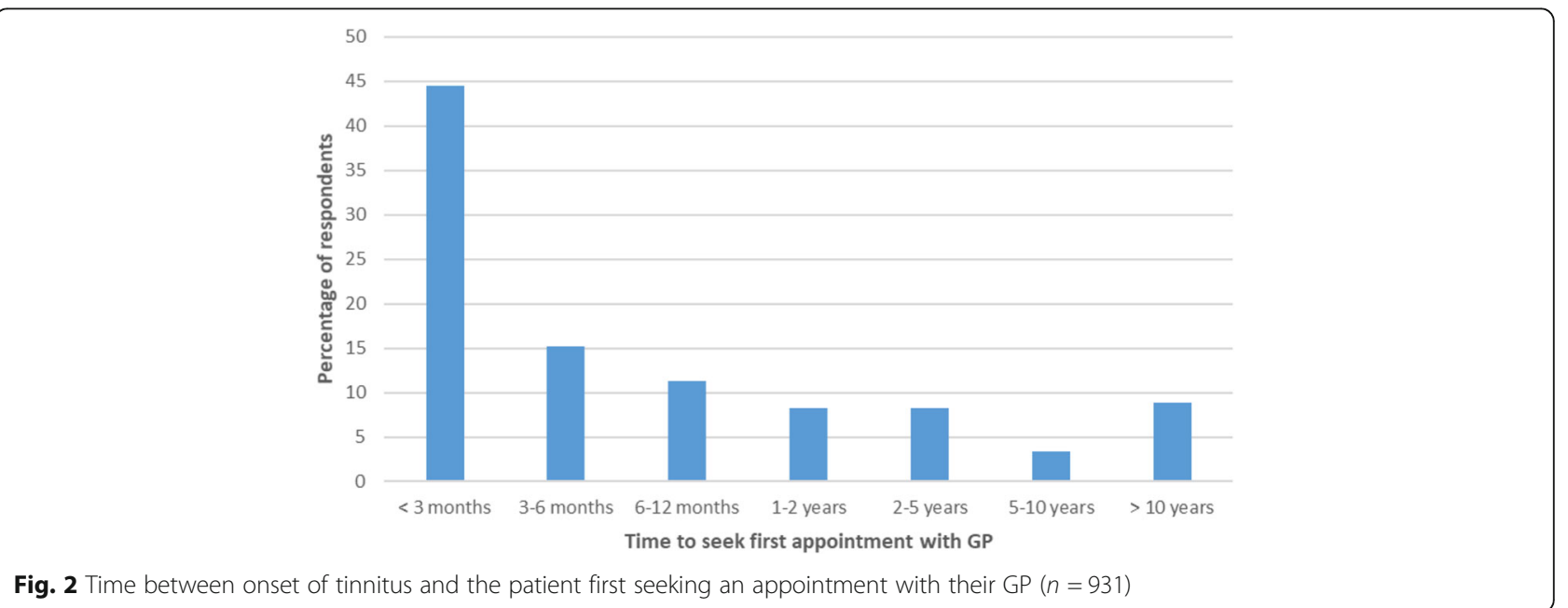


Table 2 Interventions offered at the GP consultations. Percent figures are expressed as percentages of the respondents who had consulted their GP $(n=936)$

\begin{tabular}{|c|c|c|}
\hline \multirow[t]{2}{*}{ Intervention } & \multicolumn{2}{|c|}{ Respondents } \\
\hline & $(n)$ & (\%) \\
\hline Information provided & 100 & 10.7 \\
\hline Referred to secondary care & 718 & 76.6 \\
\hline Referred to ENT or Audiovestibular Medicine (AVM) physician & 519 & 55.4 \\
\hline Referred to Audiology & 267 & 28.5 \\
\hline Referred to ENT or AVM and Audiology & 68 & 4.5 \\
\hline Medication prescribed & 188 & 20.1 \\
\hline GP follow-up appointment arranged (watchful waiting) & 32 & 3.4 \\
\hline None & 183 & 19.5 \\
\hline Hearing test at the GP surgery & 26 & 2.8 \\
\hline In-house dewaxing arranged & 9 & 1.0 \\
\hline Referred to GP colleague with special interest in ENT (GPWSI) & 10 & 1.1 \\
\hline Referred to high street service & 2 & 0.2 \\
\hline MRI arranged & 6 & 0.6 \\
\hline
\end{tabular}

question and 696 (98.0\%) reported that they had undergone a hearing test. Four had not yet been tested but had been given an appointment time for testing. Ten people reported that they had never had a hearing test.

After ENT/AVM assessment $67.7 \%$ were discharged and $32.3 \%$ of people were referred onwards to other secondary care services. The respondents who were referred onwards were generally seen in audiology departments for audiological management of their tinnitus. Some people reached audiology services by direct referral from their GPs. Overall, 273 respondents reported being seen by an audiologist and 114 by a hearing therapist. Forty-seven people were seen in audiology but were unsure whether they were under the care of an audiologist or hearing therapist. The number of appointments per respondent (Fig. 5) and the duration of these appointments (Fig. 6) varied.

Table 3 Nature and number of drugs issued to tinnitus patients in primary $(n=931)$ and secondary care $(n=294)$

\begin{tabular}{|c|c|c|c|c|}
\hline \multirow[t]{2}{*}{ Drug } & \multicolumn{2}{|c|}{ Prescribed by GP $(n=931)$} & \multicolumn{2}{|c|}{ Prescribed by ENT/AVP $(n=294)$} \\
\hline & $(n)$ & $(\%)$ & (n) & $(\%)$ \\
\hline Antibiotics (systemic and topical) & 24 & 2.58 & 1 & 0.34 \\
\hline Steroids & 2 & 0.21 & 4 & 1.36 \\
\hline Betahistine & 25 & 2.67 & 13 & 4.42 \\
\hline Vestibular sedatives & 8 & 0.86 & 3 & 1.02 \\
\hline Nasal drugs & 39 & 4.19 & 5 & 1.70 \\
\hline Cerumenolytics & 3 & 0.32 & 0 & 0 \\
\hline Beta blockers & 3 & 0.32 & 0 & 0 \\
\hline Analgesics and anti-inflammatories & 4 & 0.43 & 0 & 0 \\
\hline Anticonvulsants & 1 & 0.11 & 0 & 0 \\
\hline \multicolumn{5}{|l|}{ Psychoactive drugs } \\
\hline Antidepressants & 60 & 6.44 & 3 & 1.02 \\
\hline \multicolumn{5}{|l|}{ Hypnotics } \\
\hline Benzodiazepines & 9 & 0.97 & 0 & 0 \\
\hline Z-drugs & 8 & 0.86 & 0 & 0 \\
\hline Unspecified hypnotic & 9 & 0.97 & 1 & 0.34 \\
\hline Antipsychotics & 2 & 0.21 & 0 & 0 \\
\hline Unsure of name of drug & 15 & 1.61 & 2 & 0.68 \\
\hline
\end{tabular}




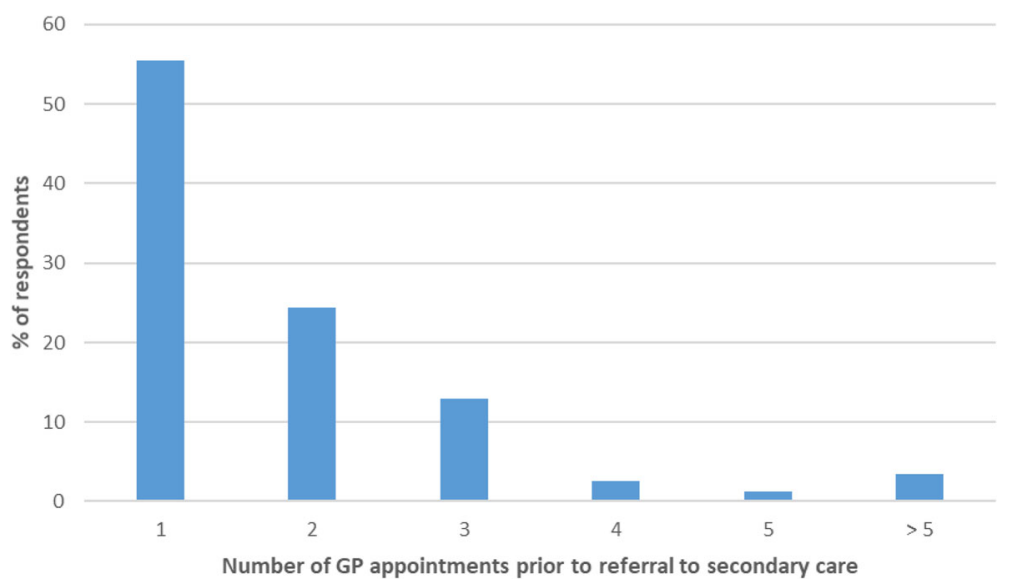

Fig. 3 The number of visits to the GP prior to referral to secondary care $(n=680)$

Two hundred seventy respondents described the tinnitus services they had received in audiology departments (Table 7). Although treatment modalities such as CBT and mindfulness meditation are typically associated with psychological services, following pioneering work by Sweetow [22] a number of audiologists and hearing therapists have trained to offer such therapies within an audiological setting. Many people reported receiving multiple treatment modalities, with a mean of 1.8 techniques per person.

Audiology departments also supply or demonstrate devices/equipment used in the management of tinnitus (Table 8). The hospital supplied equipment in 227 instances, and issued on loan in a further 24 cases. Thirty respondents reported that they bought their own equipment. Some hospitals supplied a limited range of devices/equipment such as sound generators free of charge but other items such as pillow speakers had to be purchased by patients.

Table 4 Initial referral pathways following Primary Care assessment, $n=673$

\begin{tabular}{lll}
\hline Initial referral from GP & \multicolumn{2}{l}{ Respondents } \\
\cline { 2 - 3 } & $(\mathrm{n})$ & $(\%)$ \\
\hline Hospital based ENT or Audiovestibular Medicine & 317 & 47.10 \\
Hospital based Audiology & 252 & 37.44 \\
Community Audiology & 13 & 1.93 \\
Audiology within retail premises & 3 & 0.45 \\
Hearing Therapy & 68 & 10.10 \\
Armed Forces clinic & 1 & 0.15 \\
GP with Special Interest & 1 & 0.15 \\
Tinnitus support group & 1 & 0.15 \\
Mental Health services & 1 & 0.15 \\
Radiology department & 16 & 2.38 \\
\hline
\end{tabular}

After a course of audiological management, $69.3 \%$ of respondents were discharged back to primary care or to self-manage whereas $30.7 \%$ were given an open appointment to facilitate return to audiological services if necessary.

Only 24 respondents reported that they had seen a psychologist regarding their tinnitus. Of these, 7 had received a course of CBT, 3 had received mindfulness meditation, and 4 had received both modalities. The other 10 respondents who had received a psychological intervention did not specify the approach used.

Eight hundred sixty-eight people answered the question "Have you been back to your GP regarding your tinnitus?" after discharge. Of these, 334 (38.5\%) answered in the affirmative. Two hundred eighty-six respondents were able to define the time that elapsed from discharge from hospital to return to GP (Fig. 7). 72.0\% had returned within a year and for $39.9 \%$ of the sample, return was in less than 2 months. Of the 334 people

Table 5 Diagnostic and therapeutic activities undertaken at first ENT/Audiovestibular Medicine appointment $(n=294)$

\begin{tabular}{lll}
\hline Action at first appointment & \multicolumn{2}{l}{ Respondents } \\
\cline { 2 - 3 } & $(\mathrm{n})$ & $(\%)$ \\
\hline Audiogram and/or tympanometry & 265 & 90.1 \\
MRI scan & 174 & 59.2 \\
CT scan & 4 & 1.4 \\
Ultrasound scan & 2 & 0.7 \\
Blood test & 9 & 3.1 \\
Vestibular function testing & 2 & 0.7 \\
Brainstem evoked response audiometry & 1 & 0.4 \\
Removal of wax & 3 & 1.0 \\
Insertion of ventilation tube & 1 & 0.4 \\
Prescription of drugs & 32 & 11.9 \\
\hline
\end{tabular}




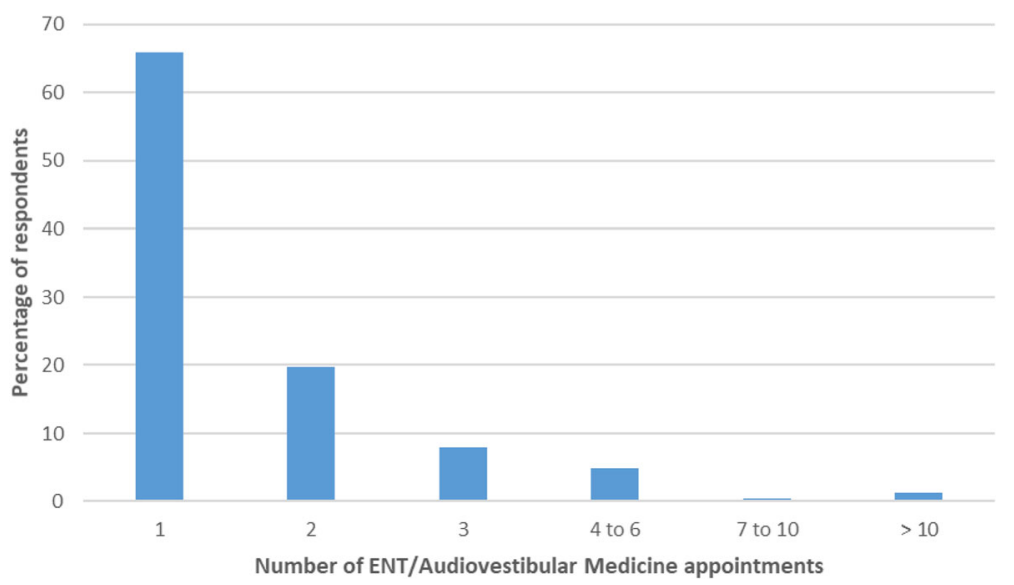

Fig. 4 The number of ENT/Audiovestibular Medicine appointments attended per respondent $(n=249)$

who went back to their GP, $122(36.5 \%)$ were referred back to secondary care.

The final tinnitus -related question in the survey invited respondents to supply any additional information that they felt would be of use. Six hundred eight people responded to this question, supplying a total of 852 separate observations. One hundred twelve respondents simply described the nature of their tinnitus. The remainder made a wide variety of statements regarding the helpfulness or otherwise of facets of tinnitus service in the UK (Table 9) or made statements regarding deficiencies in the service with suggestions for improvement (Table 10).

\section{Discussion}

This is the first account of the patient experience of tinnitus services in the UK generated from a large patient survey.

Nearly half of respondents (44.5\%) to the survey presented to their GP within three months of the onset of their tinnitus and almost three quarters had done so by the one year mark. Most respondents obtained onward referral to ENT/AVM or audiology which is similar to the findings of a survey of audiology departments [15] though only $55.4 \%$ were referred after their initial

Table 6 The location where patients underwent audiological testing

\begin{tabular}{lll}
\hline Location of audiometry & \multicolumn{2}{l}{ Respondents } \\
\cline { 2 - 3 } & (n) & $(\%)$ \\
\hline GP surgery & 26 & 3.74 \\
Audiology within retail premises & 15 & 2.16 \\
Private medical practice & 38 & 5.46 \\
Occupational audiology service & 1 & 0.14 \\
NHS Audiology service & 318 & 45.69 \\
NHS Audiology at NHS ENT/AVM appointment & 298 & 42.82 \\
\hline
\end{tabular}

consultation. Among those patients who were not referred immediately, initial management typically consisted of information provision, prescription of medication or watchful waiting. Surprisingly, almost one fifth of the respondents $(19.5 \%)$ stated that their GP took no action whatsoever at their first appointment. It is interesting to contrast patient perceptions of management with those of GPs: A survey of UK GPs [13] found that 35\% of GPs reported that they gave out information leaflets regarding tinnitus. When patients were asked a similar question in the current survey only $10.7 \%$ reported receiving information. When GPs did provide tinnitus information in the current study, they did so either directly or by referring patients to internet resources. Furthermore, a survey of the online information sites favoured by GPs has shown considerable variation in the quality of information that is offered [23].

There were some notable differences in the prescribing practices of primary care and secondary care physicians. The figures regarding drug prescription in primary care (20.1\%) tallies closely with the estimate of $17 \%$ reported in the GP survey [13]. Common prescriptions were psychoactive drugs, antibiotics, both systemic and topical, betahistine or nasal drugs such as decongestants and topical steroid sprays. In secondary care, only $10.1 \%$ received drugs and the common prescriptions were betahistine, nasal drugs and systemic steroids. The difference in overall number of prescriptions was significant (Fisher exact test $p<0.0001)$ and there was also significant difference in some of the types of prescribed drug with antibiotics, nasal drugs and antidepressant drugs more likely to be prescribed in primary care (Fisher exact test, $p=0.0159, p=0.0478$ and $p<0.0001$ respectively). By contrast, systemic steroids were more likely to be prescribed in secondary care (Fisher exact test $p=0.0322$ ). Antibiotics are clearly an appropriate management if the tinnitus has been triggered by a bacterial infection. It is, 


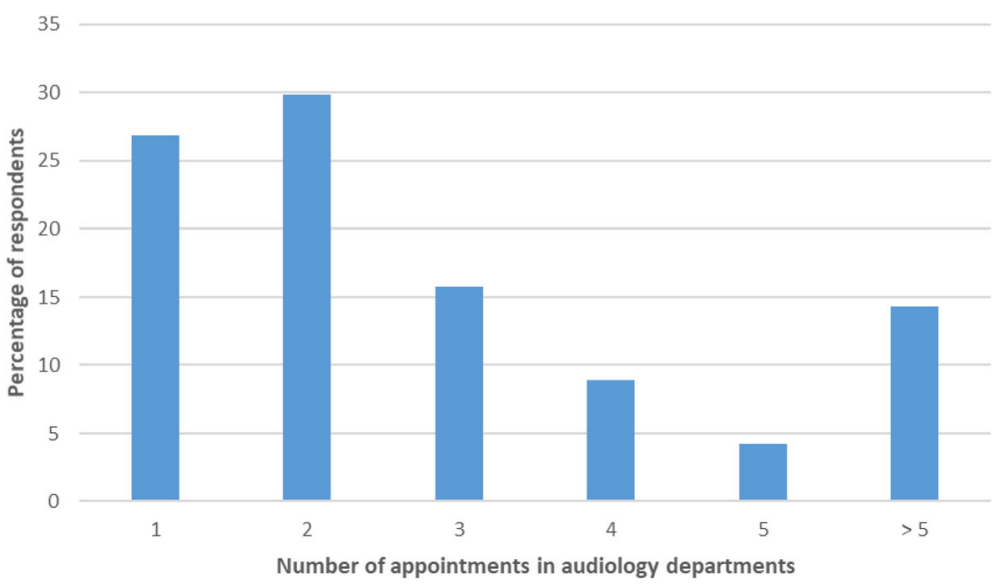

Fig. 5 The number of audiology department appointments attended per respondent $(n=405)$

however, notable that only one respondent reported receiving antibiotics from a secondary care physician. Tinnitus is not infrequently accompanied by a blocked sensation in the ear. It seems likely that physicians without access to advanced diagnostic equipment interpret this as evidence of infection and prescribe antibiotics accordingly. Similarly, this blocked sensation may be misinterpreted as evidence of Eustachian tube dysfunction. Nasal drugs to improve Eustachian tube function are then the logical treatment. There were almost 8 times more nasal drugs prescribed in primary care compared to secondary care, again suggesting that once diagnostic equipment such as tympanometers or operating microscopes were available to clinicians a more accurate diagnosis could be made. There is no robust evidence to support the use of betahistine in the management of spontaneous idiopathic tinnitus [24], but this drug may be appropriate if tinnitus is a component of Ménière's disease. In their clinical practice guidelines, Tunkel et al. [11] recommended against the use of antidepressants, anxiolytics, anticonvulsants and intra-tympanic medication for the routine treatment of persistent, bothersome tinnitus. Psychoactive drugs do, however, have a role when there is comorbid psychological illness, generally anxiety or depression [25]. The large difference in the prescription of psychoactive drugs between primary and secondary care probably reflects that ENT physicians do not feel that it is part of their remit to manage mental health conditions. Some respondents reported that they had been prescribed amitriptyline, specifically to access what is usually regarded as a side effect, namely its sedative properties.

Clinical guidelines and best practice documents recommend that all patients with tinnitus should undergo a basic audiometric assessment and ultimately the majority of respondents who answered this section of the questionnaire did undergo hearing tests. The process by which this happened appeared haphazard with multiple different pathways and no standardisation of when the testing should occur. A small number of respondents

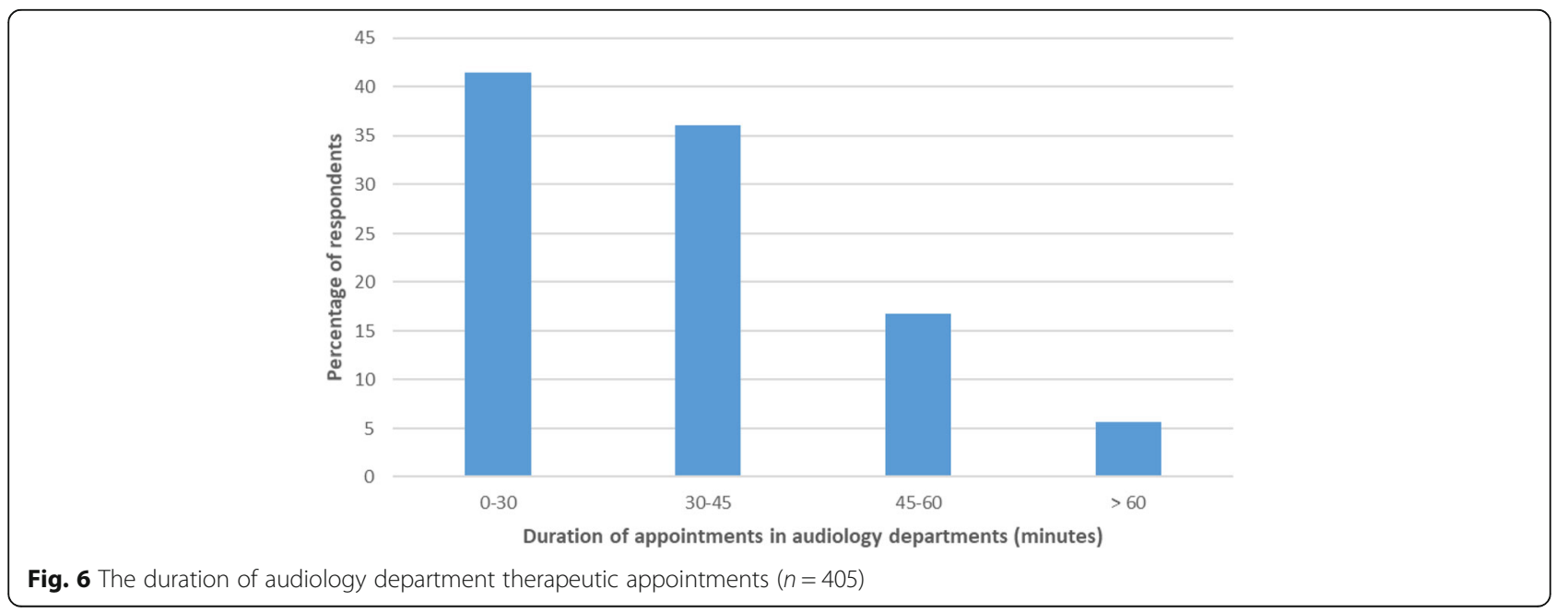


Table 7 Services offered in audiology departments for the management of tinnitus ( $n=270)$. Some respondents received more than one service

\begin{tabular}{lll}
\hline Audiology department & \multicolumn{2}{l}{ Respondents } \\
\cline { 2 - 3 } tinnitus management services & $(\mathrm{n})$ & $(\%)$ \\
\hline Written information & 180 & 66.67 \\
Sound therapy plus education & 95 & 35.19 \\
Listening strategies & 77 & 28.52 \\
Relaxation & 62 & 22.96 \\
Cognitive behavioural therapy & 29 & 10.74 \\
Mindfulness meditation & 24 & 8.89 \\
Group education & 19 & 7.04 \\
\hline
\end{tabular}

(1.1\%) reported that they had never undergone a hearing test, which does seem to be a shortcoming in their care.

After audiological testing, the only diagnostic test that was performed regularly was MRI scanning (59\% of those assessed by ENT or AVM underwent an MRI scan). The most common reasons for requesting medical imaging are unilateral or significantly asymmetric tinnitus or asymmetric audiometric tests [26]. As epidemiological studies have shown that approximately half of people with tinnitus have unilateral tinnitus [27], this rate of investigation seems appropriate. Use of such diagnostic tests carries financial implications which are discussed in a separate study [18].

It is perhaps surprising that only about a third of patients who underwent diagnostic assessment by ENT/ AVM were subsequently referred onwards for therapeutic management of their symptom. The survey made no attempt at determining the severity of individual respondents' tinnitus. It is therefore possible that some people simply wanted the reassurance of knowing there was no serious underlying pathological reason for their tinnitus and were then content to self-manage. Although figures did not reach statistical significance, a higher proportion of patients who were discharged after

Table 8 Devices supplied by audiology departments or demonstrated to patients for subsequent purchase $(n=270)$

\begin{tabular}{lll}
\hline Devices supplied or demonstrated & \multicolumn{2}{l}{ Respondents } \\
\cline { 2 - 3 } within audiology departments & $(\mathrm{n})$ & $(\%)$ \\
\hline One hearing aid & 65 & 24.07 \\
Two hearing aids & 93 & 34.44 \\
White noise generators & 91 & 33.70 \\
Combination hearing aid device - & 29 & 10.74 \\
hearing aid with sound generator & & \\
Sound therapy device e.g. table top & 44 & 16.30 \\
sound generator & & \\
Pillow speakers & 37 & 13.70 \\
Relaxation CDs & 34 & 12.59 \\
\hline
\end{tabular}

investigation returned to their GPs compared to those who were referred for audiological tinnitus management.

It is illuminating that $38.5 \%$ of patients re-presented to their GP regarding their tinnitus, and for $39.9 \%$ of these, return was within the first two months after discharge from the hospital. Of those returning to primary care, $36.5 \%$ were referred back to hospital, $24 \%$ were prescribed medication and 39\% were offered no further help. Thus, one in eight of the overall survey population went through secondary care, returned to primary care and were then re-referred to secondary care. Although this 'revolving door' pattern is well recognised in various healthcare areas such as mental health services [28] and care of the elderly [29], this is the first time the phenomenon has been reported by tinnitus patients. The survey did not explicitly ask why people went through the process two or more times, though several reasons are possible: it may be that the treatments offered were ineffective, or their tinnitus changed or that they were dissatisfied with the service they had received. A survey of GPs and ENT specialists in Western Europe, UK and USA [30] found a low success rate of tinnitus therapy. Whatever the cause, revolving door healthcare is time consuming for both patient and health care professional and carries significant financial cost implications [18].

The evidence base for the efficacy of the available tinnitus management strategies is limited but there is there is a reasonable level of scientific evidence of the effectiveness of psychological therapies particularly cognitive behaviour therapy in the management of tinnitus [3, 7]. It was therefore surprising to see that the people who commented on psychological treatment of tinnitus were more likely to describe it is as unhelpful by a factor of 2.0. Admittedly this was a very small sample $(n=6)$ and it would be wrong to read too much into the observation. However, only 24 respondents $(2.6 \%)$ reported that they had seen a psychologist. Psychological treatments were also delivered within some audiology departments by audiologists and hearing therapists. It is not standardised however and there is currently no research evidence for the effectiveness of an audiologist or hearing therapist psychological intervention [31].

Free text responses to the final tinnitus-related question in the survey give considerable insight into patients' perceptions of tinnitus services. Physicians within the tinnitus pathway were considerably more likely to be seen as unhelpful rather than helpful. One sixth of the people who replied to this question (102 of 604) were critical of their GPs management. By contrast audiologists and hearing therapists were more likely to be described as helpful, by a factor of 2.4. There are models of tinnitus care in the United Kingdom in which audiologists see tinnitus patients via direct 


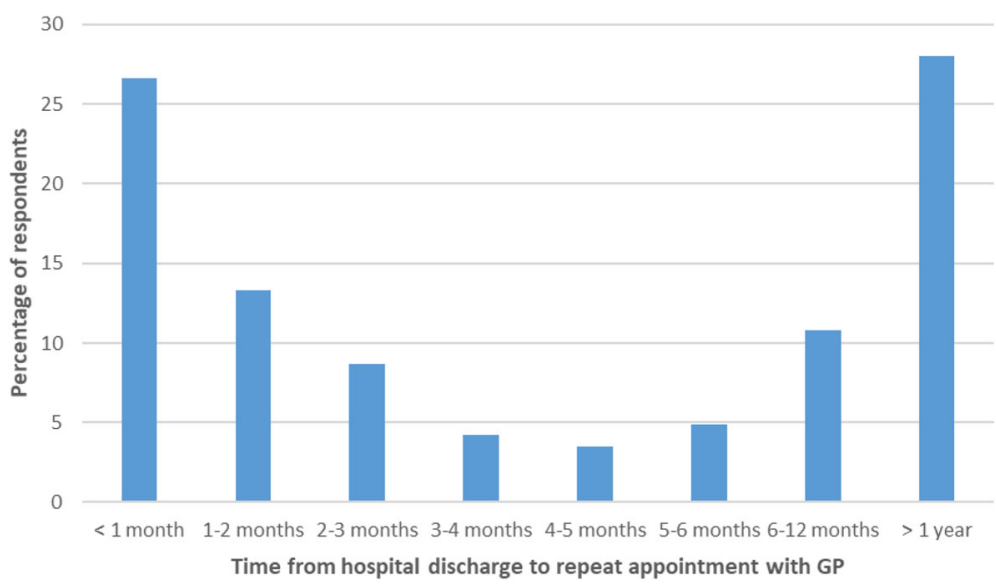

Fig. 7 The time taken from discharge from hospital to seeking a repeat appointment with the GP $(n=286)$

referral pathways and undertake the majority of the care process: this is an area that merits further investigation.

Sound therapies were generally seen as helpful. This is particularly interesting as both sound therapies and hearing aids are widely used in tinnitus clinics [32], the latter for even quite modest hearing losses, but there is scant scientific evidence regarding efficacy [33-36].

Table 9 Personnel and management strategies that people found helpful or unhelpful in their tinnitus journey $(n=608)$

\begin{tabular}{|c|c|c|c|c|}
\hline & \multicolumn{2}{|c|}{ Helpful } & \multicolumn{2}{|c|}{ Unhelpful } \\
\hline & $(n)$ & $(\%)$ & (n) & $(\%)$ \\
\hline \multicolumn{5}{|l|}{ People and departments } \\
\hline The healthcare system generally & 5 & 0.82 & 19 & 3.13 \\
\hline General Practitioners & 28 & 4.61 & 102 & 16.78 \\
\hline Hospital based services & 8 & 1.32 & 12 & 1.97 \\
\hline ENT Surgeons and Audiovestibular Physicians & 14 & 2.30 & 30 & 4.93 \\
\hline Audiologists and Hearing Therapists & 36 & 5.92 & 15 & 2.47 \\
\hline Nurses & & & 2 & 0.33 \\
\hline Community Audiology services & & & 1 & 0.16 \\
\hline High Street Audiology services & & & 4 & 0.66 \\
\hline Tinnitus support groups & 10 & 1.64 & & \\
\hline Another person with tinnitus & 2 & 0.33 & & \\
\hline \multicolumn{5}{|l|}{ Tinnitus management } \\
\hline Hearing aids & 31 & 5.10 & 7 & 1.15 \\
\hline Sound therapy devices & 14 & 2.30 & 3 & 0.99 \\
\hline Psychological treatments & 2 & 0.33 & 4 & 0.66 \\
\hline Medication (hypnotics or antidepressants) & 3 & 0.49 & 1 & 0.16 \\
\hline Having open access to support services & 6 & 0.99 & & \\
\hline \multicolumn{5}{|l|}{ Sources of information } \\
\hline Charities & 23 & 3.78 & & \\
\hline Internet & 9 & 1.48 & 1 & 0.16 \\
\hline
\end{tabular}

The most common factor that people would like to see improved was the speed of delivery of tinnitus services: $7.0 \%$ of people who answered this question felt that they had experienced unacceptable delay. Although this was seen as a problem within GP and ENT services,

Table 10 Observations regarding tinnitus services, including unhelpful attitudes and suggestions for improvements $(n=604)$

Respondents

(n) (\%)

Comments regarding tinnitus services

Services poor or unavailable locally: had to travel $\quad 12 \quad 1.99$

Paid for private treatment $\quad 32 \quad 5.23$

Had to go through the system more than once: $\quad 8 \quad 1.32$

"revolving door" healthcare

$\begin{array}{lll}\text { Had to be very persistent to obtain referral } & 21 & 3.48\end{array}$

to tinnitus services

$\begin{array}{lll}\text { Learnt to self-manage tinnitus } & 12 & 1.99\end{array}$

$\begin{array}{lll}\text { Gave up interacting with healthcare services } & 2 & 0.33\end{array}$

Factors that would improve tinnitus services

More information

$\begin{array}{lll}\text { A quicker service from tinnitus services } & 42 & 6.95\end{array}$

More extensive diagnostic services $\quad 15 \quad 2.48$

Easier booking of follow-up appointments $\quad 8 \quad 1.32$

$\begin{array}{lll}\text { Easier access to audiology } & 2 & 0.33\end{array}$

$\begin{array}{lll}\text { Easier access to psychology } & 6 & 0.99\end{array}$

More general recognition and awareness $\quad 31 \quad 5.13$

More knowledge of local tinnitus options $\quad 9 \quad 1.49$

by General Practitioners

$\begin{array}{lll}\text { More research and /or a cure } & 19 & 3.15\end{array}$

Negative experience of tinnitus services

$\begin{array}{lll}\text { Told by healthcare professional that nothing } & 201 & 33.28\end{array}$ can be done/they will have to live with the tinnitus

Patient concluded that nothing can be done/they will have to live with the tinnitus 
other issues may be involved. Clinical Commissioning Groups in some cases stipulate that patients with tinnitus should not be immediately referred to secondary care. For example, the guidelines produced by North East Essex Clinical Commissioning Group [37] recommend referral only if there is (1) consistent bilateral tinnitus (persistent for over 20 weeks) and hearing loss, or (2) unilateral tinnitus (persistent over 2 months). Exploring other forms of tinnitus intervention may help to deliver a more timely service. For example, internet delivered CBT has been successfully trialled in other countries [38]. A pilot study has been undertaken in the UK and more rigorous research is underway [39-42]. The effectiveness and cost effectiveness of these alternative pathways need to be investigated.

\section{Strengths and weaknesses}

Strengths of this study include a large sample size and the fact that the survey achieved good representation from all health regions of the UK. Furthermore, the age and gender demographics of the survey population are broadly congruent with those seen in epidemiological studies of tinnitus. The use of Internet-based questionnaires is a contentious topic in healthcare research. Internet-based questionnaires offer several advantages over other data collection methods - distributing the survey is quicker and cheaper than paper, telephone and face-to-face surveys. Completing Internet surveys is quicker for participants than a telephone interview. There are however, some limitations of Internet questionnaires that may introduce bias $[42,43]$. The response rate of Internet-based questionnaires is generally lower than with other forms of data collection and, in particular, there is a tendency for participants in Internet based studies not to complete all sections of the survey. Poor overall response rates can cause selection bias. Failure to answer all sections can generate response bias. A potential source of sampling bias is the makeup of the database that was used to contact participants. People interacting with the BTA may have more intrusive tinnitus than average or may be interacting with the charity because they are dissatisfied with the service that their healthcare providers have supplied. The age of participants may also be relevant. Government statistics show that $89 \%$ of the UK population interact regularly with the Internet but this varies from $99 \%$ in the 16 -34 year old age range to $41 \%$ in those over 75 [44]. This means that any internet-based questionnaire is likely to target younger participants disproportionately.

The study was retrospective and reliant on people's memories. Some had experienced tinnitus for a considerable length of time, with $11.95 \%$ reporting that it was more than 10 years since they had first consulted their GP. This may introduce recall bias.
A further limitation might be the restrictiveness of some of the survey response options: a limited number of choices was offered without an 'other' category on some questions. The survey may have missed capturing data on components such as 'self-management' or on uncommonly used treatment possibilities. This can generate response bias. However, the survey did not insist that every question was answered and it was not a forced choice questionnaire. Free text entry was utilised at various points and participants were encouraged to include any comments that they thought might be relevant.

\section{Conclusions}

In comparison with most other countries, the UK has well developed tinnitus services with a network of audiology departments offering a range of tinnitus management paradigms and in England's case a national best practice document. Asking the end user, however, tells a different story: one fifth of patients reported that at initial consultation their GP did nothing; two thirds of people who are referred for diagnostic services in secondary care are then discharged without any therapeutic intervention; one in eight people with tinnitus are referred from primary to secondary care, discharged and then re-referred to secondary care, creating expensive and unsatisfactory revolving door healthcare; only one in forty are able to access psychological services for tinnitus, despite an evidence base that suggests psychological treatments are the most efficacious management strategies. One third of patients report nihilistic attitudes from healthcare professionals. Clearly change is needed: tinnitus management at primary care, counselling/CBT in secondary care, and alternative referral pathways are priorities for both research and service development.

\section{Additional file}

Additional file 1: Survey questionnaire: A tinnitus patient's journey. The online questionnaire that was circulated to participants in the study. (DOCX $15 \mathrm{~kb}$ )

\section{Abbreviations \\ ACT: Acceptance and Commitment Therapy; AVM: Audiovestibular Medicine; BTA: British Tinnitus Association; CBT: cognitive behavioural therapy; CT: Computed Tomography; ENT: Ear Nose and Throat; GP: General Practitioner; MRI: Magnetic resonance imaging; NICE: National Institute for Health and Care Excellence}

\section{Acknowledgements}

We would like to thank Emily Broomhead of the British Tinnitus Association for her help in development and administration of the survey questionnaire. We would also like to thank Lucy Handscomb of University College London for advising on certain parts of the text.

Funding

No external funding was received. 


\section{Availability of data and materials}

The data that support the findings of this study are available from the British Tinnitus Association but restrictions apply to the availability of these data, which were used under license for the current study, and so are not publicly available. Data are however available from the authors upon reasonable request and with permission the British Tinnitus Association.

\section{Authors' contributions}

DS and DM designed the study. DS oversaw development of the questionnaire. DM and DJH extracted and analysed the data. JR and SC developed the draft manuscript. All authors edited and approved the final manuscript as submitted and agreed to be accountable for all aspects of the work.

\section{Ethics approval and consent to participate}

Not applicable: as this study was a retrospective service evaluation and used only highly anonymised data for the sole purpose of service evaluation, individual consent was not sought, and research ethics committee review was not required [19].

\section{Consent for publication}

Not applicable.

\section{Competing interests}

DM has paid consultancies with Otonomy and has received payment for trials of drugs for tinnitus (GSK and Autifony) and has received payment for providing tinnitus talks to healthcare professionals and the public. DM has received royalties for books on tinnitus. JR has received payment for trials of drugs for tinnitus (Otonomy and Autifony). DS is Chief Executive of a tinnitus charity (British Tinnitus Association). DJH is funded by the NIHR Biomedical Research Centre Programme. The views expressed in this article are those of the authors and not necessarily those of the NIHR, the NHS, or the Department of Health.

\section{Publisher's Note}

Springer Nature remains neutral with regard to jurisdictional claims in published maps and institutional affiliations.

\section{Author details}

${ }^{1}$ Colchester Hospital University NHS Foundation Trust, Department of Otolaryngology, Essex County Hospital, Lexden Rd, Colchester, Essex CO3 3NB, UK. ${ }^{2}$ NIHR Nottingham Hearing Biomedical Research Centre, Otology and Hearing Group, Division of Clinical Neuroscience, University of Nottingham, Nottingham NH1 5DU, UK. ${ }^{3}$ Regional Department of Neurotology, Department of Otolaryngology, Royal Hallamshire Hospital, Sheffield S10 2JF, UK. "British Tinnitus Association, Ground Floor, Unit 5, Acorn Business Park, Woodseats Close, Sheffield S8 OTB, UK

\section{Received: 21 December 2016 Accepted: 6 February 2018}

\section{Published online: 13 February 2018}

\section{References}

1. McCormack A, Edmondson-Jones M, Somerset S, Hall D. A systematic review of the reporting of tinnitus prevalence and severity. Hear Res. 2016; 337:70-9.

2. Davis A, El Rafaie A. Epidemiology of tinnitus. In: Tyler RS, editor. Tinnitus handbook. San Diego: Singular, Thomson Learning; 2000. p. 1-23.

3. Hoare DJ, Kowalkowski VL, Kang S, Hall DA. Systematic review and metaanalyses of randomized controlled trials examining tinnitus management. Laryngoscope. 2011:121:1555-64.

4. Baguley D, McFerran D, Hall D. Tinnitus. Lancet. 2013;382:1600-7.

5. Andersson G. Clinician-supported internet-delivered psychological treatment of tinnitus. Am J Audiol. 2015;24:299-301.

6. Hesser $H$, Weise $C$, Westin VZ, Andersson G. A systematic review and metaanalysis of randomized controlled trials of cognitive-behavioral therapy for tinnitus distress. Clin Psychol Rev. 2011;31:545-53.

7. Martinez-Devesa P, Perera R, Theodoulou M, Waddell A. Cognitive behavioural therapy for tinnitus. Cochrane Database Syst Rev. 2010, Issue 9. Art. No.: CD005233. doi: https://doi.org/10.1002/14651858.CD005233.pub3.

8. Philippot P, Nef F, Clauw L, de Romrée M, Segal Z. A randomized controlled trial of mindfulness-based cognitive therapy for treating tinnitus. Clin Psychol Psychother. 2012;19:411-9.
9. Westin VZ, Schulin M, Hesser $H$, et al. Acceptance and commitment therapy versus tinnitus retraining therapy in the treatment of tinnitus: a randomised controlled trial. Behav Res Ther. 2011:49:737-47.

10. Department of Health. Provision of Services for Adults with Tinnitus. A Good Practice Guide. Jan 28, 2009. http://webarchive.nationalarchives.gov.uk/ 20130107105354/http:/www.dh.gov.uk/prod_consum_dh/groups/dh digitalassets/documents/digitalasset/dh_093810.pdf Accessed 22 Jan 2018.

11. Tunkel DE, Bauer CA, Sun GH, Rosenfeld RM, Chandrasekhar SS, Cunningham ER Jr, Archer SM, Blakley BW, Carter JM, Granieri EC, Henry JA, Hollingsworth D, Khan FA, Mitchell S, Monfared A, Newman CW, Omole FS, Phillips CD, Robinson SK, Taw MB, Tyler RS, Waguespack R, Whamond EJ. Clinical practice guideline: tinnitus. Otolaryngol Head Neck Surg. 2014;151(2 Suppl):S1-S40.

12. National Institute for Health and Care Excellence, Clinical Knowledge Summary regarding management of tinnitus. http://cks.nice.org.uk/tinnitus. Accessed 12 July 2017

13. El-Shunnar SK, Hoare DJ, Smith S, Gander PE, Kang S, Fackrell K, Hall DA Primary care for tinnitus: practice and opinion among GPs in England. J Eval Clin Pract. 2011:17:684-92.

14. Hoare DJ, Gander PE, Collins L, Smith S, Hall DA. Management of tinnitus in English NHS audiology departments: an evaluation of current practice. $J$ Eval Clin Pract. 2012;18:326-34

15. Gander PE, Hoare DJ, Collins L, Smith S, Hall DA. Tinnitus referral pathways within the National Health Service in England: a survey of their perceived effectiveness among audiology staff. BMC Health Serv Res. 2011;11:162.

16. Aazh H, Moore BC, Lammaing K, Cropley M. Tinnitus and hyperacusis therapy in a UK National Health Service audiology department: Patients' evaluations of the effectiveness of treatments. Int J Audiol. 2016:55:514-22.

17. British Tinnitus Association. http://www.tinnitus.org.uk. Accessed 22 Jan 2018.

18. Stockdale D, McFerran D, Brazier P, Pritchard C, Kay T, Dowrick C, Hoare DJ. An economic evaluation of the healthcare cost of tinnitus management in the UK. BMC Health Serv Res. 2017;17:577.

19. Health Research Authority 2017. http://www.hra-decisiontools.org.uk/ research/ Accessed 22 Jan 2018.

20. Survey Monkey (https://www.surveymonkey.com/). Accessed 22 Jan 2018.

21. Overview of the UK population: February 2016. Office for National Statistics. https://www.ons.gov.uk/peoplepopulationandcommunity/ populationandmigration/populationestimates/articles/ overviewoftheukpopulation/february2016. Accessed 22 Jan 2018.

22. Sweetow RW. Cognitive aspects of tinnitus patient management. Ear Hear. 1986;7:390-6.

23. Fackrell K, Hoare DJ, Smith S, McCormack A, Hall DA. An evaluation of the content and quality of tinnitus information on websites preferred by general practitioners. BMC Med Inform Decis Mak. 2012;12:70.

24. Beebe Palumbo D, Joos K, De Ridder D, Vanneste S. The management and outcomes of pharmacological treatments for tinnitus. Curr Neuropharmacol. 2015;13:692-700.

25. Dauman R, Tyler RS. Some considerations on the classification of tinnitus. In: Aran JM, Dauman R, editors. Tinnitus 91 - proceedings of the fourth international tinnitus seminar. Amsterdam: Kugler Publications; 1992. p. 225-9.

26. British Academy of Audiology Guidance for Onward Referral of Adults with Hearing Difficulty Directly Referred to Audiology. http://www.baaudiology. org/files/4614/7828/2156/BAA Guidance for Onward Referral of Adults with_Hearing_Difficulty_Directly_Referred_to_Audiology_2016.pdf. Accessed 12 July 2017.

27. Coles RRA. Epidemiology of tinnitus: (2) demographics and clinical features. J Laryngol Otol. 1984;9:195-202.

28. Rabinowitz J, Mark M, Popper M, Slyuzberg M, Munitz H. Predicting revolving-door patients in a 9-year national sample. Soc Psychiatry Psychiatr Epidemiol. 1995;30:65-72.

29. Walter R. The revolving door of hospital readmissions. Caring. 1998;17:56-9.

30. Hall DA, Láinez MJ, Newman CW, Sanchez TG, Egler M, Tennigkeit F, Koch M, Langguth B. Treatment options for subjective tinnitus: self reports from a sample of general practitioners and ENT physicians within Europe and the USA. BMC Health Serv Res. 2011;11:302

31. Thompson DM, Hall DA, Walker DM, Hoare DJ. Psychological therapy for people with tinnitus: a scoping review of treatment components. Ear Hear. 2017:38:149-58.

32. Hoare DJ, Searchfield GD, El Refaie A, Henry JA. Sound therapy for tinnitus management: practicable options. J Am Acad Audiol. 2014;25:62-75.

33. Noble W. Treatments for tinnitus. Trends Amplif. 2008;12:236-41. 
34. Cabral J, Tonocchi R, Ribas Â, Almeida G, Rosa M, Massi G, Berberian AP. The efficacy of hearing aids for emotional and auditory tinnitus issues. Int Tinnitus J. 2016;20:54-8.

35. Hoare DJ, Edmondson-Jones M, Sereda M, Akeroyd MA, Hall D. Amplification with hearing aids for patients with tinnitus and co-existing hearing loss. Cochrane Database Syst Rev. 2014;31(1):CD010151.

36. Hobson J, Chisholm E, El Refaie A. Sound therapy (masking) in the management of tinnitus in adults. Cochrane Database Syst Rev. 2012;11:CD006371.

37. North East Essex Clinical Commissioning Group (2016) http://www. neessexccg.nhs.uk/uploads/files/Clinical\%20Priorities\%20Policy_ From\%2016\%20Feb\%202017\%20(Version\%202.8).pdf. Accessed 22 Jan 2018.

38. Weise C, Kleinstäuber M, Andersson G. Internet-delivered cognitive-behavior therapy for tinnitus: a randomized controlled trial. Psychosom Med. 2016;78: 501-10.

39. Beukes EW, Allen PM, Manchaiah V, Baguley DM, Andersson G. Internetbased intervention for tinnitus: outcome of a single-group open trial. J Am Acad Audiol. 2017;28:340-51.

40. Beukes EW, Manchaiah V, Allen PM, Baguley DM, Andersson G. Internetbased cognitive behavioural therapy for adults with tinnitus in the UK: study protocol for a randomised controlled trial. BMJ Open. 2015;5:e008241.

41. Greenwell K, Sereda M, Coulson N, Hoare DJ. Understanding user reactions and interactions with an internet-based intervention for tinnitus selfmanagement: mixed-methods process evaluation protocol. JMIR Res Protoc. 2016;5:e49.

42. Heiervang E, Goodman R. Advantages and limitations of web-based surveys: evidence from a child mental health survey. Soc Psychiatry Psychiatr Epidemiol. 2011;46:69-76.

43. van Gelder MM, Bretveld RW, Roeleveld N. Web-based questionnaires: the future in epidemiology? Am J Epidemiol. 2010;172:1292-8.

44. Internet users in the UK: 2017. Office for National Statistics. https://www.ons. gov.uk/businessindustryandtrade/itandinternetindustry/bulletins/ internetusers/2017. Accessed 22 Jan 2018

\section{Submit your next manuscript to BioMed Central and we will help you at every step:}

- We accept pre-submission inquiries

- Our selector tool helps you to find the most relevant journal

- We provide round the clock customer support

- Convenient online submission

- Thorough peer review

- Inclusion in PubMed and all major indexing services

- Maximum visibility for your research

Submit your manuscript at www.biomedcentral.com/submit 